\title{
Variability in serum sodium concentration and prognostic significance in severe traumatic brain injury: a multi-center observational study
}

Anatole Harrois ${ }^{1,2}$, James R Anstey ${ }^{1}$, Mathieu van der Jagt ${ }^{3}$, Fabio S Taccone ${ }^{4}$, Andrew A Udy ${ }^{5,15}$, Giuseppe Citerio ${ }^{6}$, Jacques Duranteau ${ }^{2}$, Carole Ichai ${ }^{7}$, Rafael Badenes ${ }^{8}$, John R Prowle ${ }^{9}$, Ari Ercole $^{10}$, Mauro Oddo ${ }^{11}$, Antoine Schneider ${ }^{11}$, Stefan Wolf ${ }^{12}$, Raimund Helbok ${ }^{13}$, David W Nelson ${ }^{14}$, D Jamie Cooper ${ }^{5,15}$, Rinaldo Bellomo ${ }^{1,15,16,17}$ on behalf of The TBI Collaborative

Data collection: Long $K^{1}$, Rodrigues $A^{2}$, Lozano $A^{4}$, Saxby $E^{5}$, Vargiolu $A^{6}$, Quintard $H^{7}$, Guillemes $\mathrm{M}^{8}$, Sisson $\mathrm{A}^{9}$, Allen $\mathrm{G}^{10}$, Baro $\mathrm{N}^{12}$, Kofler $\mathrm{M}^{13}$

\section{Affiliations \& Contact details}

1. Intensive Care Unit, Level 5, B Block, Royal Melbourne Hospital, Parkville, 3050 Victoria, Australia

2. Department of Anesthesia and Surgical Intensive Care, Paris Sud University, CHU de Bicetre, Le Kremlin Bicêtre, 78, rue du Général Leclerc 94275 Le Kremlin-Bicêtre, France

3. Department of Intensive Care Adults, Erasmus MC-University Medical Center| Dr Molewaterplein 40, 3015 GD, Po Box 2040, 3000 CA Rotterdam, The Netherlands

4. Department of Intensive Care, Erasme Hospital, Université Libre de Bruxelles, Route de Lennik, 808, 1070 Brussels, Belgium

5. Intensive Care Unit, The Alfred Hospital, Commercial Road, Melbourne, Victoria, Main Ward Block, Level 1, Commercial Rd, Melbourne VIC 3004, Australia

6. School of Medicine and Surgery, University Milano Bicocca - Neurointensive Care, San Gerardo Hospital, ASSTMonza, Monza, Italy

7. Université Côte d'Azur, Center hospitalier Universitaire de Nice, Service de Réanimation polyvalente, Hôpital Pasteur 2. 30 Voie Romaine. CHU de Nice. 06000 Nice, France

8. Department of Anesthesiology and Surgical-Trauma Intensive Care, Hospital Clinic Universitari de Valencia, Department of Surgery, University of Valencia, Valencia, Spain

9. Adult Critical Care Unit, The Royal London Hospital, Barts Health NHS Trust, Royal London Hospital, Whitechapel Road, London E1 1BB, UK

10. Neurosciences and Trauma Critical Care Unit, Cambridge University Hospitals NHS Foundation Trust, Cambridge, UK

11. Department of Medical-Surgical Intensive Care Medicine, Faculty of Biology and Medicine, Center Hospitalier Universitaire, Vaudois (CHUV), University of Lausanne, Lausanne, 1011, Switzerland

12. Department of Neurosurgery, Charité Universitätsmedizin Neuro Intensive Care Unit 102i , Campus Charité Mitte (CCM), Charitéplatz 1, 10117 Berlin, Germany

13. Department of Neurology, Neurocritical Care Unit, Medical University of Innsbruck, Anichstr.35, 6020 Innsbruck, Austria

14. Section for Perioperative Medicine and Intensive Care, Department of Physiology and Pharmacology, Karolinska Institute, S-171 76 Stockholm, Sweden 
15. Australian and New Zealand Intensive Care Research Center, School of Public Health and Preventative Medicine, Monash University, ANZIC-RC, Department of Epidemiology and Preventive Medicine, Monash University, Level 3, 553 St Kilda Road, Melbourne VIC 3004 Australia

16. Department of Intensive Care, Austin Health, 145 Studley Rd, Heidelberg, Melbourne, Victoria, Australia

17. Center for Integrated Critical Care, School of Medicine, University of Melbourne, Melbourne, Australia

\section{Corresponding author:}

Dr Anatole Harrois, PhD

Department of Anesthesia and Surgical Intensive Care, Paris Sud University, CHU de Bicetre, Le Kremlin Bicêtre, 78, rue du Général Leclerc 94275 Le Kremlin-Bicêtre, France

The analysis of this multicentre study was performed in the Intensive Care Unit of the Royal Melbourne Hospital

Word count: 3106

4 Tables, 1 Figure

Funding: This study has received no funding (grant, support)

The authors declare that they have no conflict of interest 


\section{Details page}

The manuscript complies with all the instructions for authors

The final manuscript was approved by all the authors

This manuscript has not been published elsewhere and is not under consideration by another journal

Ethics approval for contribution to this dataset was obtained locally by each center.

This study followed the STROBE recommendation for observational studies (appendix 1) 


\section{Abstract}

Background/Objective: Dysnatremia is common in severe traumatic brain injury (TBI) patients and may contribute to mortality. However, serum sodium variability has not been studied in TBI patients. We hypothesized that such variability would be independently associated with mortality.

Methods: We collected 6-hourly serum sodium levels for the first 7 days of ICU admission from 240 severe TBI patients in 14 neurotrauma ICUs in Europe and Australia. We evaluated the association between daily serum sodium standard deviation ( $\left.\mathrm{dNa}_{\mathrm{SD}}\right)$, an index of variability, and 28-day mortality.

Results: Patients were $46 \pm 19$ years of age with a median initial GCS of 6 [ $4-8$ ]. Overall hospital mortality was $28 \%$. Hypernatremia and hyponatremia occurred in $64 \%$ and $24 \%$ of patients, respectively. Over the first 7 days in ICU, serum sodium standard deviation was 2.8 [2.0 - 3.9] $\mathrm{mmol} / \mathrm{L}$. Maximum daily serum sodium standard deviation ( $\mathrm{dNasD}$ ) occurred at a median of 2 [14] days after admission. There was a significant progressive decrease in dNasD over the first 7 days (coefficient $-0.1595 \% \mathrm{Cl}[-0.18--0.12], \mathrm{p}<0.001)$. After adjusting for baseline TBI severity, diabetes insipidus, the use of osmotherapy, the occurrence of hypernatremia and hyponatremia and center, dNaSD was significantly independently associated with 28-day mortality (HR 1.27 $95 \% \mathrm{Cl}(1.01-1.61), \mathrm{p}=0.048)$.

Conclusions: Our study demonstrates that daily serum sodium variability is an independent predictor of 28-day mortality in severe TBI patients. Further prospective investigations are 
necessary to confirm the significance of sodium variability in larger cohorts of TBI patients and test whether attenuating such variability confers outcome benefits to such patients.

Keywords: Sodium variability, traumatic brain injury, hypernatremia, hyponatremia, osmotherapy 


\section{Introduction}

Serum sodium concentration is tightly regulated in humans. However, severe traumatic brain injury (TBI) patients are at high-risk of developing dysnatremia due to the use of hyperosmolar therapy, diabetes insipidus[1] and inappropriate water retention. As both hypernatremia and hyponatremia have been reported to be independently associated with mortality and worse outcome in TBI patients[2-4], serum sodium management appears an important therapeutic target in patients with raised intracranial pressure. However, given their potential to induce osmotic injury to neurons [5-7], it would seem plausible that, independent of hypo or hypernatremia, changes in sodium concentration may be at least as pathophysiologically important as the serum sodium concentration itself.

Outside the context of TBI, in order to gain further insights into the association between serum sodium disorders and outcome, several authors have considered serum sodium variability over time $[8,9]$. In these studies, serum sodium variability was associated with mortality independently of the serum sodium level itself. We therefore hypothesized that, in a population of severe TBI patients, serum sodium variability would be associated with mortality regardless of the occurrence of hyponatremia and hypernatremia. In order to test this hypothesis, in an international multicenter cohort study of severe TBI patients, we sought to assess the daily variability of serum sodium over the first 7 days of intensive care unit (ICU) stay and its relationship with 28-day mortality. 


\section{Methods}

We have provided a STROBE (Strengthening the reporting of observational studies in epidemiology) checklist in Supplementary Appendix 1. Ethics approval for contribution to this dataset was obtained locally by each center.

\section{Study population}

We retrospectively collected data on previously managed patients in 14 Intensive Care Units (ICUs) treating TBI patients. The description of data collection has been described previously [10]. Two centers were from Australia (both from Melbourne), and the remaining 12 were from Europe (London and Cambridge, UK; Paris and Nice, France; Valencia, Spain; Lausanne, Switzerland; Brussels, Belgium; Monza, Italy; Berlin, Germany; Rotterdam, The Netherlands; Solna, Sweden and Innsbruck, Austria).

We included the first 20 patients admitted to each center in 2015 (except two centers that included 14 and 10 patients, respectively). Inclusion criteria were age $\geq 18$ years, severe TBI as defined by a Glasgow Coma Scale (GCS) of 8 or less after resuscitation but before sedation, and an intracranial pressure (ICP) monitor in place for at least 72 hours. Patients dying within 48 hours of ICU admission were excluded in order to focus on those with a potentially salvageable injury.

\section{Data collection}

Each center retrospectively collected demographic, clinical and biochemical data. Baseline admission data included age, sex, GCS, pupil reactivity, hemoglobin, blood glucose levels and brain computed tomography CT-scan findings as required to calculate the Marshall score and illness severity scores: injury severity score (ISS), Acute Physiology and Chronic Health Evaluation 
score (APACHE-II) and International Mission for Prognosis and Analysis of Clinical trial in TBI score (IMPACT-score, core + CT + lab) for each patient.

We collected six-hourly serum sodium concentrations from ICU admission until 7 days, or death, whichever came first. We collected data on important aspects of TBI care including neurosurgery (clot evacuation, extra-ventricular drainage, decompressive craniectomy) as well as the use of osmotherapy[10], barbiturate coma and hypothermia (less than $35^{\circ} \mathrm{C}$ ) and daily total desmopressin administered. Finally, we collected outcome data including ICU and hospital mortality, and ICU and hospital length of stay.

\section{Definition of serum sodium variability}

We defined daily serum sodium variability as the daily standard deviation of serum sodium measurements (dNasd) for each individual for each day over the first seven days of admission. We also calculated serum sodium variability as the standard deviation of all serum sodium measurements taken during the seven-day period ( $\mathrm{NaSD}$ ) after admission for each patient. We defined patients with high sodium variability as those having a Nass greater than the median NasD for the whole cohort. We used this threshold since no data are available on serum sodium variability in TBI patients.

\section{Generation of variables}

Natremia on admission was defined as the first available sodium concentration after admission to ICU. Hyponatremia and hypernatremia were defined as at least one serum sodium value below $135 \mathrm{mmol} / \mathrm{L}$ or above $145 \mathrm{mmol} / \mathrm{L}$, respectively[11]. The minimum and maximum sodium $\left(\mathrm{Na}_{\min }\right.$ and $\left.\mathrm{Na}_{\max }\right)$ concentrations for each patient were taken to be the lowest and highest measured serum sodium concentrations over the first 7 days of their ICU stay. Mean 
serum sodium concentration was calculated for each patient as the mean $\left(\mathrm{Na}_{\text {mean }}\right)$ of all serum sodium measurements taken during the seven-day period. Since serum sodium was measured 6hourly, $\mathrm{Namean}$ was equivalent to a time-weighted average serum sodium. We also calculated daily maximum sodium $\left(\mathrm{dNa} a_{\max }\right)$, daily minimum sodium $\left(\mathrm{dNa}_{\mathrm{min}}\right)$, daily mean serum sodium $(\mathrm{dNa} \mathrm{Nean})$ for each of the 7 first days of admission.

We defined two thresholds for acute serum sodium changes (increases or decreases) as changes of 3 or 6 mmoles between two serum sodium measures (i.e. over 6 hours), corresponding to rates of change higher than 0.5 and $1.0 \mathrm{mmol} / \mathrm{L} / \mathrm{h}$ respectively[11].

We defined center ${ }_{\text {high }}$ as the center with the highest mean serum sodium over the first 7 days of ICU stay and center low as the center with the lowest mean serum sodium over the first 7 days. We used desmopressin administration as a surrogate marker of central diabetes insipidus[12].

\section{Missing data}

Patients with $50 \%$ or more missing data were not included in the analysis. For patients with less than $50 \%$ missing data, we interpolated missing serum sodium values by assigning the mean value of the previous and the next available serum sodium measure.

\section{$\underline{\text { Serum sodium measurement }}$}

Serum sodium measurement was performed by blood gas analyzers in each ICU, except in two centers where a small number of samples were sent to the central lab. In each center, analyzer maintenance was performed as recommended by the manufacturer with at least one daily autocalibration.

\section{$\underline{\text { Statistical analysis }}$}

We expressed quantitative variables as means (standard deviation) or medians [interquartile range] while categorical variables were expressed as counts (proportion). We compared 
normally-distributed variables with a t-test and used a Chi-square test to compare proportions. For non-normally distributed variables, we used the Mann-Whitney test.

We analyzed the effect of time on dNass with a linear mixed model with time as a fixed effect and patient as a random effect. In order to assess changes in six-hourly serum sodium over time in center low, center ${ }_{\text {high }}$ and the remaining centers, we built 2 linear mixed models to compare center $_{\text {low }}$ with the remaining centers and center $_{\text {high }}$ with the remaining centers over the first 7 days of ICU admission, by considering center as a fixed effect and patient as a random effect.

To compare the impact of mannitol and HTS on serum sodium measurements in univariate analysis, we used a linear mixed model with mannitol and HTS as 2 different fixed effects (and included an interaction between mannitol and HTS) and patient as a random effect.

In order to assess sensitivity to missing sodium measures, we conducted all linear mixed models in the whole cohort and in the subpopulation of patients without missing sodium measures.

We first compared in a univariate analysis the characteristics of survivors and non survivors. We then examined the relationship between 28 -day mortality and variables that had a $p$-value $<0.10$ in univariate analysis ( $d N a_{\text {SD }}$ as a measure of daily sodium variability, $\mathrm{dNa}_{\max }, \mathrm{dNa}$ min ) by applying a Cox proportional-hazards regression model. This model analyzed the relationship between time to mortality (up to 28 days) and these variables. We adjusted the model for baseline risk of death (IMPACT score) and for other known confounding risk factors for death (diabetes insipidus, osmotherapy, hypernatremia and hyponatremia) $[2,13]$. Diabetes insipidus was considered as a daily time-dependent variable whose value was 0 and became 1 on the first day desmopressin was given. Hypertonic saline and mannitol were both considered as time-dependent variables whose values were 1 on the days they were given and 0 on the days they were not administered. Hypernatremia and hyponatremia were considered as time-dependent covariates with an assigned value of 0 on those days when they were absent and a value of 1 if at least one serum 
sodium measure was higher than $145 \mathrm{mmol} / \mathrm{L}$ (hypernatremia) or below $135 \mathrm{mmol} / \mathrm{L}$ (hyponatremia) that day. By adjusting for the occurrence of daily hyponatremia and hypernatremia, we aimed to investigate whether daily fluctuations in serum sodium as quantified by daily serum sodium standard deviation are associated with outcome regardless of the level of the serum sodium level they fluctuate around. To account for variations in dNasD (i.e., daily variations in $\mathrm{Na}_{S D}$ ), we considered $\mathrm{dNa}_{\mathrm{SD}}$ as a continuous time-varying variable whose daily value was included in the model. This approach limits the risk of "survivor treatment selection bias" that would have been encountered if sodium variability had been considered as a time-fixed variable [14]. We accounted for center effect by adding center as a random effect in the multivariable Cox proportional hazard regression model. In order to assess sensitivity of our Cox model to missing serum sodium measures, we also applied, as recommended elsewhere [15], a multiple imputation method for missing data in repeated measurements using a fully conditionnal specification method for regularly spaced data (MICE package for R) and calculated hazard ratios from this imputed dataset.

The two-sided level of significance was fixed at $5 \%$. We analyzed results using $\mathrm{R}$ open source software 3.4.1 (http ://www.R-project.org). 


\section{Results}

\section{General characteristics of study patients}

We collected data on 262 patients. We excluded 22 patients because of more than $50 \%$ missing sodium values. From the 240 patients included in the analysis, we obtained 5,806 serum sodium measurements. We collected serum sodium over a median of 6 [5-7] days. There were 185 missing serum sodium measures (3.2\%) in 57 patients that were imputed according to the study protocol. Additional description of missing sodium measures is provided in Table 1 of the Supplementary Appendix 2.

The characteristics of the study population are described in Table 1. Patients were predominantly middle-aged males with a median Injury Severity Score of 30 [25-41]. Median GCS prior to sedation was 6 [4-8]. One third had at least one fixed pupil at hospital admission. About one-third of patients underwent neurosurgery for clot evacuation. Overall hospital mortality was $28 \%$. A comparison of characteristics in patients without missing sodium and those with missing sodium measures is provided in table 2 of the Supplementary Appendix 2.

\section{General description of serum sodium}

Table 1 summarizes serum sodium values of the study population. Hypernatremia and hyponatremia occurred in 153 (64\%) and 58 (24\%) patients respectively. Moreover, 74 (48\%) of those developing hypernatremia had received hypertonic saline over the first 7 days of admission. When considering the mean serum sodium by center over the first 7 days of admission, the median $\mathrm{Namean}_{\text {mas }} 143.1$ [142.7-144.4] mmol/L with differences of greater than $10 \mathrm{mmol} / \mathrm{L}$ between some centers. Serum sodium levels were significantly different between center $_{\text {low, }}$ center ${ }_{\text {high }}$ and all other centers over time (Figure 1 of the Supplementary Appendix 3, $\mathrm{p}<0.001$ ). Similar results were found when excluding patients with missing sodium measures 
(Table 1 of the Supplementary Appendix 3). The evolution of ICP over the first 7 days of admission is shown in Supplementary Appendix 4.

\section{Serum sodium variability}

Over the first 7 days of ICU stay, median NasD was $2.8[2.0-3.9] \mathrm{mmol} / \mathrm{L}$. Median dNasD was 1.3 [0.8-1.9] $\mathrm{mmol} / \mathrm{L}$. Maximum dNasD occurred at a median of 2 [1-4] days after admission. Figure 1 shows $d \mathrm{Na}_{s D}, \mathrm{dNa}_{\text {mean }}, \mathrm{dNa}_{\max }$ and $\mathrm{dNa}_{\min }$ over the first seven days of admission. There was a significant progressive decrease in dNasD over the first 7 days (coefficient $-0.1595 \% \mathrm{Cl}[-0.18$ - 0.12], $p<0.001)$. Similar results were found when excluding patients with missing sodium measures (Supplementary Appendix 5).

A comparison of patients experiencing NasD higher than $2.8 \mathrm{mmol} / \mathrm{L}$ (i.e. median NasD in the cohort over the first 7 days in ICU) with those having NasD lower than $2.8 \mathrm{mmol} / \mathrm{L}$ is shown in Table 2. Patients with high NasD received more desmopressin and osmotherapy and had higher ISS. Moreover, patients with high NasD were more likely to experience hyper and hyponatremia (Table 2).

Serum sodium decreased by at least $0.5 \mathrm{mmol} / \mathrm{L} / \mathrm{h}$ in $3.3 \%$ of 6 -hourly episodes (i.e. $14 \%$ of days with such a rapid decrease in serum sodium), and by at least $1.0 \mathrm{mmol} / \mathrm{L}$ in $0.5 \%$ of 6 -hourly episodes. Serum sodium increased by at least $0.5 \mathrm{mmol} / \mathrm{L} / \mathrm{h}$ in $5.3 \%$ of 6 -hourly episodes (i.e. $21 \%$ of days with such a rapid increase in serum sodium), and by at least $1.0 \mathrm{mmol} / \mathrm{L} / \mathrm{h}$ in $1.0 \%$ of 6-hourly episodes (Table 1). Acute six-hourly increases in serum sodium (i.e. six-hourly increase of more than 0.5 or $1.0 \mathrm{mmol} / \mathrm{L} / \mathrm{h}$ ) occurred more often in patients with high NasD. ICU and hospital mortality were higher in patients with a high NasD than those with a low NasD but it did not reach statistical significance. 
Both mannitol and hypertonic saline affected $d \mathrm{Na}_{\mathrm{sD}}$ in the same way (Supplementary Appendix 6). HTS was associated with the occurrence of hypernatremia, an increased $\mathrm{Namean}_{\text {man }}$ and $\mathrm{Namax}$ while mannitol was associated with the occurrence of hyponatremia and with more common acute serum sodium changes (Supplementary Appendix 6). Similar results were found when excluding patients with missing sodium measures (Supplementary Appendix 6). 2 centers exclusively used mannitol, 3 centers exclusively used hypertonic saline whereas 9 centers used both agents.

\section{Relationship between serum sodium variability and outcome}

General characteristics and serum sodium levels of survivors and non-survivors are presented in Table 3. $\mathrm{Namax}_{\max }$ and $\mathrm{Na}_{\text {mean }}$ were significantly different between survivors and non-survivors. $\mathrm{Na}_{\min }$ and $\mathrm{Na}_{\text {SD }}$ were not significantly different between survivors and non-survivors. Acute increases in six-hourly measured serum sodium (i.e. a rise in six-hourly serum sodium of more than 0.5 or $1.0 \mathrm{mmol} / \mathrm{L} / \mathrm{h}$ ) were significantly more common in non-survivors than survivors while hyponatremia and hypernatremia were not.

When individually including variables that had a $p$-value $<0.10$ in univariate analysis between survivors and non survivors ( $\left.\mathrm{dNa}_{\max }, \mathrm{dNa}_{\min }, \mathrm{dNa} \mathrm{sD}_{\mathrm{s}}\right)$ in a Cox proportional hazards model for mortality, adjusted for baseline severity (IMPACT score), the occurrence of diabetes insipidus, the use of osmotherapy, and the occurrence of hypernatremia or hyponatremia, only dNasD was significantly associated with 28-day mortality (HR $1.2795 \% \mathrm{Cl}(1.01-1.61), \mathrm{p}=0.048$, Table 4). Of note, hypernatremia and hyponatremia were not independently associated with 28-day mortality in this model ( $\mathrm{HR} 1.7395 \% \mathrm{Cl}(0.94-3.20), \mathrm{p}=0.08$ and $0.74(0.24-2.28), \mathrm{p}=0.60$ respectively). Similar results were found when applying the same Cox proportional hazards 
model to data imputed with a multiple imputation method for missing data in repeated measurements using a fully conditionnal specification method for regularly spaced data (Supplementary Appendix 7). 


\section{Discussion}

\section{Key findings}

In an international multi-center study, we aimed to analyze daily serum sodium variability over the first seven days of ICU stay, and its relationship with 28-day mortality. We found that sodium variability was highest during the first 2 days after admission and progressively decreased thereafter. We also found that variability of serum sodium (as reflected by its daily standard deviation), even after adjustment for TBI severity, diabetes insipidus, osmotherapy, hyponatremia and hypernatremia, was a significant predictor of mortality. To our knowledge, this is a novel finding in severe TBI patients.

\section{Relationship with previous studies}

Severe TBI leads to disorders of serum sodium and water handling [16]. While some factors such as the use osmotherapy, the use of fluids with high sodium content, and choice of nutritional preparations are at the discretion of the physician, other factors are trauma-related, such as the occurrence of posterior pituitary dysfunction $[17,18]$. In the latter case, a deficit in antidiuretic hormone $(A D H)$ secretion results in water loss and hypernatremia, whereas excessive ADH secretion leads to water retention and the risk of hyponatremia[19]. In TBI patients, the prevalence of hyponatremia and hypernatremia has been reported between 15 to $55 \%[4,13,20-$ $22]$ and 30 to $50 \%,[2,23,24]$ respectively. In keeping with these studies, we found that $24 \%$ of patients experienced hyponatremia. Our finding that $64 \%$ of patients experienced hypernatremia during the period of observation is higher than previously described, and likely explained by the greater frequency of measurement in our study. 
Our study shows that even within academic centers in Europe and Australia there is marked variability in serum sodium levels according to center. Such high variability between centers should be interpreted in the context of previous conflicting results in TBI patients[5,25,26], which suggests that the optimal level of serum sodium remains unclear. Similar to what has been described in general ICU patients[8,27], serum sodium variability was highest over the first 2 days in our cohort of severe TBI patients and the extent of serum sodium variability was similar in our study population to that previously reported in burns patients[27]. Studies of serum sodium report a greater occurrence of dysnatremias in neuro-critical care patients $[2,20,24]$ compared to general ICU patients[8,28,29]. Accordingly, risk factors for increased dNasD included osmotherapy and desmopressin administration.

As expected, mannitol was associated with more common hyponatremia whereas HTS led to a higher incidence of hypernatremia. Mannitol-induced hyponatremia is a non-hypotonic hyponatremia and may thus not have the same meaning as true hyponatremia. Mannitol was also associated with more acute changes in serum sodium than HTS. Whether this relates to the osmotic drug in itself or some unmeasured confounders remains to be investigated.

Unlike absolute sodium concentration[2,4,23], any association that may exist between serum sodium variability and outcome has not been investigated in TBI patients. In our study, after adjusting for baseline severity and previously described key confounding factors influencing serum sodium level[2], serum sodium variability, as assessed by $\mathrm{dNa}$ sD, was associated with 28day mortality. Moreover, this association was independent of the occurrence of daily hyponatremia and hypernatremia, which suggests that fluctuations in sodium leading to an increased $\mathrm{dNa}$ SD are associated with mortality at any sodium level. Serum sodium standard 
deviation does not capture the rate of serum sodium change. However, those patients with high serum sodium variability had more periods of rapid sodium change, raising the possibility that acute variations in sodium might partly account for the relationship between $\mathrm{dNasD}$ and outcome. Indeed, a retrospective analysis of the subset of TBI patients in the SAFE study who received the relatively hypotonic ( $260 \mathrm{mOsm} / \mathrm{L}$ ) $4 \%$ albumin solution rather than $0.9 \%$ sodium chloride as resuscitation fluid, raised the possibility that the mechanism of increased mortality in those receiving albumin was related to episodes of increased ICP [30] induced by rapid changes in osmolarity.

\section{Implications of study findings}

Our findings imply that, in TBI patients, serum sodium variability is independently associated with mortality. This variability is highest during the first 2 days of ICU stay. Mannitol use potentially leads to greater sodium changes than hypertonic saline. As dNasD is potentially a modifiable risk factor for mortality, further investigation is needed to determine whether attenuation of such variability may be beneficial to patients.

\section{Strengths and limitations}

Our study has several strengths. It is the first international multicenter study describing the independent association of $\mathrm{dNasD}$ with mortality. Thus, across a wide spectrum of behavior and sodium management, our findings still hold and have external validity within such a spectrum of practice. Moreover, serum sodium was measured six-hourly during the first week after ICU admission and on more than 5,000 occasions, providing the most robust and detailed assessment to date of serum sodium changes over time in TBI patients. In addition, we collected daily use of osmotherapy as well as desmopressin, allowing us to account for important causes of sodium 
variability that may have confounded the association of serum sodium with death in other studies.

We acknowledge several limitations. This is a retrospective study with all the inherent limitations of such studies. However, sodium levels are objective, reproducible, and not subject to selection or ascertainment bias, and mortality is a clear patient-centered outcome. We had $3.2 \%$ missing sodium measures, nonetheless, our findings were robust to different approaches to imputation and linear mixed models were not sensitive to missing sodium measures. We did not measure neurological outcome. This would have required systematic follow-up at 6 months or one year. This shortcoming will have to be addressed in future studies of sodium variability. As this study was not a randomized controlled trial, we can make no inferences as to causality. While we adjusted for TBI severity, we could not adjust for ICP elevations, which are a major clinical variable triggering therapeutic interventions, potentially including intentional changes in serum sodium. Thus, it remains possible that serum sodium variability is simply a marker of illness severity. However, if this is the case, such variability appears to be a more powerful risk factor than hypernatremia and hyponatremia and should be taken into account in future predictive models for mortality in TBI patients.

\section{Conclusion}

In summary, in an international multicenter study, we found that serum sodium variability, as reflected by its daily standard deviation, has an independent association with mortality, after adjustment for $\mathrm{TBI}$ severity and key confounders. Further prospective investigations are necessary to confirm the significance of sodium variability in larger cohorts of TBI patients and test whether attenuating such variability confers outcome benefits to such patients. 


\section{Acknowledgements}

We would ask that the authors be acknowledged individually.

Harrois $A^{1,2^{*}}$, Anstey $\mathrm{JR}^{1}$, van der Jagt $\mathrm{M}^{3}$, Taccone $\mathrm{FS}^{4}, \mathrm{Udy} A \mathrm{~A}^{5,15}$, Citerio $\mathrm{G}^{6}$, Duranteau $\mathrm{J}^{2}$, Ichai $C^{7}$, Badenes $R^{8}$, Prowle $J R^{9}$, Ercole $A^{10}$, Oddo $M^{11}$, Schneider $A^{11}$, Wolf $S^{12}$, Helbok $R^{13}$, Nelson $\mathrm{DW}^{14}$, Cooper DJ $\mathrm{J}^{5,15}$, Bellomo $\mathrm{R}^{1,15,16,17}$ on behalf of The TBI Collaborative

(affiliations below)

We would also ask that the data collectors be acknowledged for their contribution.

Long $K^{1}$, Rodrigues $A^{2}$, Lozano $A^{4}$, Saxby $E^{5}$, Vargiolu $A^{6}$, Quintard $H^{7}$, Guillemes $M^{8}$, Sisson $A^{9}$, Allen $\mathrm{G}^{10}$, Baro $\mathrm{N}^{12}$, Kofler $\mathrm{M}^{13}$

(affiliations below)

\section{Author disclosure statement}

No competing financial interests exist. 


\section{References}

1. Kleindienst A, Hannon MJ, Buchfelder M, Verbalis JG. Hyponatremia in Neurotrauma: The Role of Vasopressin. J Neurotrauma. 2016;33:615-24.

2. Maggiore U, Picetti E, Antonucci E, Parenti E, Regolisti G, Mergoni M, et al. The relation between the incidence of hypernatremia and mortality in patients with severe traumatic brain injury. Crit Care Lond Engl. 2009;13:R110.

3. Aiyagari V, Deibert E, Diringer MN. Hypernatremia in the neurologic intensive care unit: how high is too high? J Crit Care. 2006;21:163-72.

4. Moro N, Katayama Y, Igarashi T, Mori T, Kawamata T, Kojima J. Hyponatremia in patients with traumatic brain injury: incidence, mechanism, and response to sodium supplementation or retention therapy with hydrocortisone. Surg Neurol. 2007;68:387-93.

5. Lescot T, Degos V, Zouaoui A, Préteux F, Coriat P, Puybasset L. Opposed effects of hypertonic saline on contusions and noncontused brain tissue in patients with severe traumatic brain injury. Crit Care Med. 2006;34:3029-33.

6. Melton JE, Patlak CS, Pettigrew KD, Cserr HF. Volume regulatory loss of $\mathrm{Na}, \mathrm{Cl}$, and $\mathrm{K}$ from rat brain during acute hyponatremia. Am J Physiol. 1987;252:F661-669.

7. Verbalis JG. Brain volume regulation in response to changes in osmolality. Neuroscience. 2010;168:862-70.

8. Sakr Y, Rother S, Ferreira AMP, Ewald C, Dünisch P, Riedemmann N, et al. Fluctuations in serum sodium level are associated with an increased risk of death in surgical ICU patients. Crit Care Med. 2013;41:133-42.

9. Ye X, Kooman JP, van der Sande FM, Canaud B, Stuard S, Etter M, et al. Increased Mortality Associated with Higher Pre-Dialysis Serum Sodium Variability: Results of the International MONitoring Dialysis Outcome Initiative. Am J Nephrol. 2019;49:1-10.

10. Anstey J, Taccone F, Udy A, Citerio G, Duranteau J, Ichai C, et al. Early osmotherapy in severe traumatic brain injury: an international multicentre study. J Neurotrauma [Internet]. 2019 [cited 2019 Aug 5]; Available from:

https://www.liebertpub.com/doi/10.1089/neu.2019.6399

11. Sterns RH. Disorders of Plasma Sodium - Causes, Consequences, and Correction.

Ingelfinger JR, editor. N Engl J Med. 2015;372:55-65.

12. The TBI Collaborative, Harrois A, Anstey JR, Taccone FS, Udy AA, Citerio G, et al. Serum sodium and intracranial pressure changes after desmopressin therapy in severe traumatic brain injury patients: a multi-centre cohort study. Ann Intensive Care [Internet]. 2019 [cited 2019 Sep 12];9. Available from:

https://annalsofintensivecare.springeropen.com/articles/10.1186/s13613-019-0574-z

13. Yumoto T, Sato K, Ugawa T, Ichiba S, Ujike Y. Prevalence, risk factors, and short-term consequences of traumatic brain injury-associated hyponatremia. Acta Med Okayama. 2015;69:213-8.

14. Shintani AK, Girard TD, Eden SK, Arbogast PG, Moons KGM, Ely EW. Immortal time bias in critical care research: Application of time-varying Cox regression for observational cohort studies*: Crit Care Med. 2009;37:2939-45.

15. Huque MH, Carlin JB, Simpson JA, Lee KJ. A comparison of multiple imputation methods for missing data in longitudinal studies. BMC Med Res Methodol [Internet]. 2018 [cited 2020 May 3];18. Available from:

https://bmcmedresmethodol.biomedcentral.com/articles/10.1186/s12874-018-0615-6 16. Kleindienst A, Brabant G, Morgenthaler NG, Dixit KC, Parsch H, Buchfelder M. Following brain trauma, copeptin, a stable peptide derived from the AVP precusor, does not reflect 
osmoregulation but correlates with injury severity. Acta Neurochir Suppl. 2010;106:221-4. 17. Hannon MJ, Crowley RK, Behan LA, O'Sullivan EP, O'Brien MMC, Sherlock M, et al. Acute glucocorticoid deficiency and diabetes insipidus are common after acute traumatic brain injury and predict mortality. J Clin Endocrinol Metab. 2013;98:3229-37.

18. Agha A, Thornton E, O'Kelly P, Tormey W, Phillips J, Thompson CJ. Posterior pituitary dysfunction after traumatic brain injury. J Clin Endocrinol Metab. 2004;89:5987-92.

19. Harrois A, Anstey JR. Diabetes Insipidus and Syndrome of Inappropriate Antidiuretic Hormone in Critically III Patients. Crit Care Clin. 2019;35:187-200.

20. Human T, Cook AM, Anger B, Bledsoe K, Castle A, Deen D, et al. Treatment of Hyponatremia in Patients with Acute Neurological Injury. Neurocrit Care. 2017;27:242-8.

21. Lohani S, Devkota UP. Hyponatremia in patients with traumatic brain injury: etiology, incidence, and severity correlation. World Neurosurg. 2011;76:355-60.

22. Meng X, Shi B. Traumatic Brain Injury Patients With a Glasgow Coma Scale Score of $\leq 8$, Cerebral Edema, and/or a Basal Skull Fracture are More Susceptible to Developing Hyponatremia. J Neurosurg Anesthesiol. 2016;28:21-6.

23. Vedantam A, Robertson CS, Gopinath SP. Morbidity and mortality associated with hypernatremia in patients with severe traumatic brain injury. Neurosurg Focus. 2017;43:E2. 24. Li M, Hu YH, Chen G. Hypernatremia severity and the risk of death after traumatic brain injury. Injury. 2013;44:1213-8.

25. Asehnoune K, Lasocki S, Seguin P, Geeraerts T, Perrigault PF, Dahyot-Fizelier C, et al. Association between continuous hyperosmolar therapy and survival in patients with traumatic brain injury - a multicentre prospective cohort study and systematic review. Crit Care [Internet]. 2017 [cited 2018 Dec 5];21. Available from: https://ccforum.biomedcentral.com/articles/10.1186/s13054-017-1918-4

26. Wells DL, Swanson JM, Wood GC, Magnotti LJ, Boucher BA, Croce MA, et al. The relationship between serum sodium and intracranial pressure when using hypertonic saline to target mild hypernatremia in patients with head trauma. Crit Care Lond Engl. 2012;16:R193. 27. Sen S, Tran N, Chan B, Palmieri TL, Greenhalgh DG, Cho K. Sodium variability is associated with increased mortality in severe burn injury. Burns Trauma. 2017;5:34.

28. Stelfox HT, Ahmed SB, Zygun D, Khandwala F, Laupland K. Characterization of intensive care unit acquired hyponatremia and hypernatremia following cardiac surgery. Can J Anaesth J Can Anesth. 2010;57:650-8.

29. Stelfox HT, Ahmed SB, Khandwala F, Zygun D, Shahpori R, Laupland K. The epidemiology of intensive care unit-acquired hyponatraemia and hypernatraemia in medical-surgical intensive care units. Crit Care Lond Engl. 2008;12:R162.

30. Cooper DJ, Myburgh J, Heritier S, Finfer S, Bellomo R, Billot L, et al. Albumin resuscitation for traumatic brain injury: is intracranial hypertension the cause of increased mortality? J

Neurotrauma. 2013;30:512-8. 
Figure 1

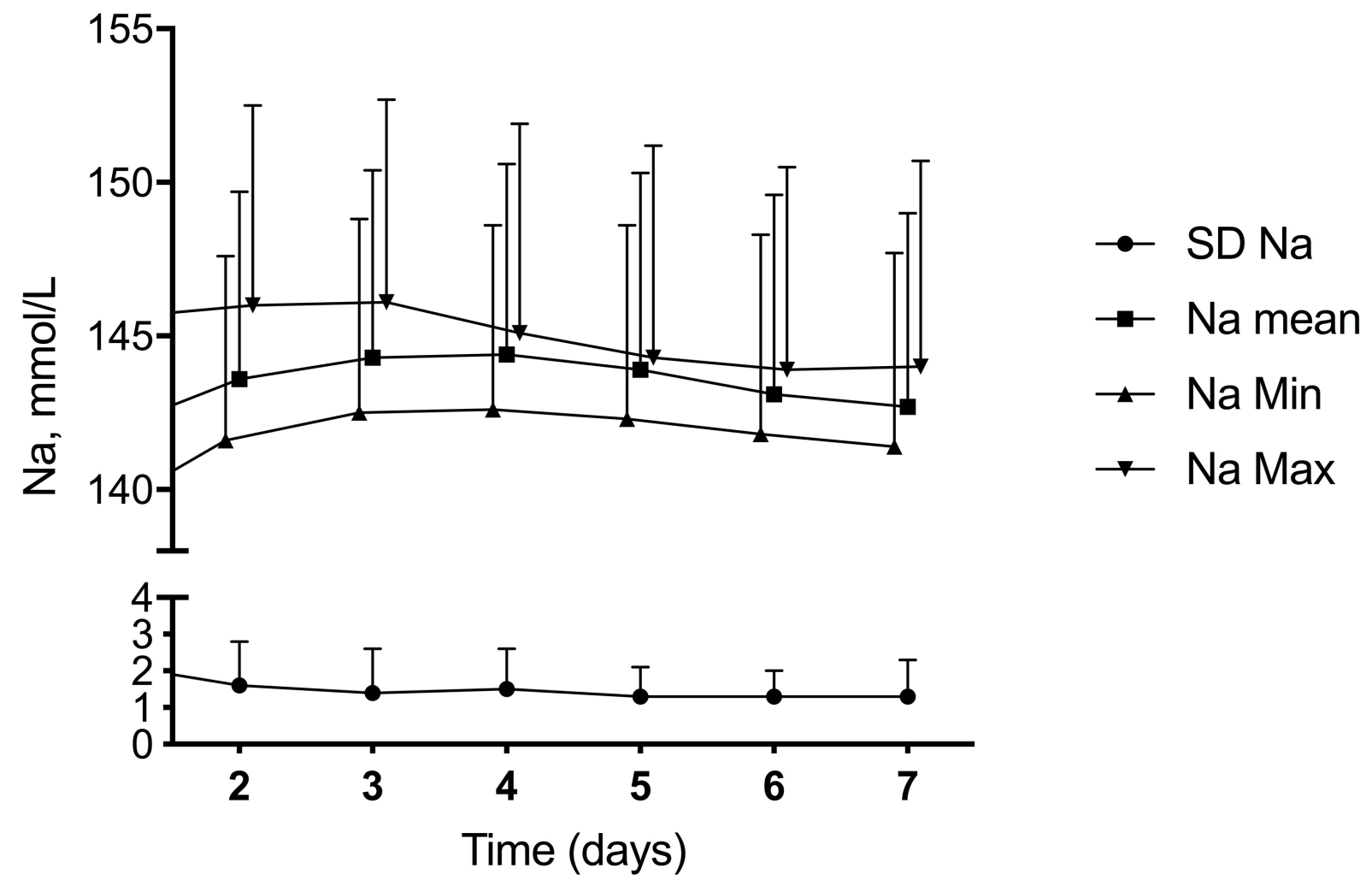


Table 1 : Clinical and serum sodium characteristics of the study population.

\begin{tabular}{|c|c|}
\hline Variable & Value \\
\hline \multicolumn{2}{|l|}{ Clinical characteristics } \\
\hline Age, years & $46 \pm 19$ \\
\hline Weight, kg & $76 \pm 13$ \\
\hline Male, n (\%) & $186(78)$ \\
\hline GCS prior to sedation & $6[4-8]$ \\
\hline At least one fixed pupil at admission, $\mathrm{n}(\%)$ & $79(33)$ \\
\hline Marshall score & $3[2-5]$ \\
\hline Injury Severity Score & $30[25-41]$ \\
\hline APACHE II Score & $19[15-24]$ \\
\hline Extended IMPACT predicted 6 month-mortality, \% & $25[14-39]$ \\
\hline Neurosurgery (for clot evacuation), $\mathrm{n}(\%)$ & $90(38)$ \\
\hline Extra-ventricular drain, $\mathrm{n}(\%)$ & $82(34)$ \\
\hline Hypothermia $\leq 35^{\circ} \mathrm{C}, \mathrm{n}(\%)$ & $59(26)$ \\
\hline Barbiturate, $\mathrm{n}(\%)$ & $27(11)$ \\
\hline Decompressive craniectomy, $\mathrm{n}(\%)$ & $70(29)$ \\
\hline ICU mortality, n(\%) & $57(24)$ \\
\hline Hospital mortality, $\mathrm{n}(\%)$ & $66(28)$ \\
\hline \multicolumn{2}{|l|}{ First Natremia in ICU } \\
\hline Admission natremia, $\mathrm{mmol} / \mathrm{L}$ & 140 [137-143] \\
\hline \multicolumn{2}{|l|}{ Hypernatremia within the first 7 days } \\
\hline Hypernatremia >145 mmol/L, $\mathrm{n}(\%)$ & $153 / 240(64)$ \\
\hline Time from admission to hypernatremia $>145 \mathrm{mmol} / \mathrm{L}, \mathrm{h}$ & $24[12-60]$ \\
\hline \multicolumn{2}{|l|}{ Hyponatremia within the first 7 days } \\
\hline Hyponatremia <135 mmol/L, $\mathrm{n}(\%)$ & $58 / 240(24)$ \\
\hline Time from admission to hyponatremia $<135 \mathrm{mmol} / \mathrm{L}, \mathrm{h}$ & $24[6-111]$ \\
\hline \multicolumn{2}{|l|}{ Acute Serum Sodium changes within the first 7 days * } \\
\hline Serum sodium increase $>0.5 \mathrm{mmol} / \mathrm{L} / \mathrm{h}, \mathrm{n}(\%)$ & $294 / 5566(5.3)$ \\
\hline Serum sodium increase $>1 \mathrm{mmol} / \mathrm{L} / \mathrm{h}, \mathrm{n}(\%)$ & $55 / 5566(1.0)$ \\
\hline Serum sodium decrease $>0.5 \mathrm{mmol} / \mathrm{L} / \mathrm{h}, \mathrm{n}(\%)$ & $186 / 5566(3.3)$ \\
\hline Serum sodium decrease $>1.0 \mathrm{mmol} / \mathrm{L} / \mathrm{h}, \mathrm{n}(\%)$ & $26 / 5566(0.5)$ \\
\hline \multicolumn{2}{|l|}{ Serum sodium according to center within the first 7 days } \\
\hline Mean serum sodium (all centers, $\mathrm{Na}_{\text {mean }}$ ), $\mathrm{mmol} / \mathrm{L}$ & $143 \pm 5$ \\
\hline Mean Serum Sodium (center ${ }_{\text {high }}$ ), $\mathrm{mmol} / \mathrm{L}$ & $149 \pm 6$ \\
\hline Mean Serum Sodium (center ${ }_{\text {low }}$ ), $\mathrm{mmol} / \mathrm{L}$ & $138 \pm 4$ \\
\hline \multicolumn{2}{|l|}{ Serum sodium extreme values within the first 7 days } \\
\hline Minimum Serum Sodium $\left(\mathrm{Na}_{\min }\right), \mathrm{mmol} / \mathrm{L}$ & $137[135-140]$ \\
\hline Maximum Serum Sodium $\left(\mathrm{Na}_{\max }\right), \mathrm{mmol} / \mathrm{L}$ & $147[144-152]$ \\
\hline \multicolumn{2}{|l|}{ Serum sodium variability within the first 7 days } \\
\hline Standard deviation of serum sodium $\left(\mathrm{Na}_{\mathrm{SD}}\right), \mathrm{mmol} / \mathrm{L}$ & $2.8[2.0-3.9]$ \\
\hline
\end{tabular}

\footnotetext{
* Acute changes in serum sodium are given in number of six-hourly period of time with rate of change greater than 0.5 or $1 \mathrm{mmol} / \mathrm{L} / \mathrm{h}$. Data are reported as mean $\pm \mathrm{SD}$, median [interquartile ranges] or $\mathrm{n}$ (proportion). APACHE = acute physiology and chronic health evaluation, EVD = extraventricular drain, GCS = Glasgow Coma Scale, ICU = intensive care unit, IMPACT = international mission for prognosis and analysis of clinical trials in TBI, ISS = injury severity score. center $_{\text {high }}=$ the single center with the highest mean serum sodium level over the first 7 days of admission, center $_{\text {low }}=$ the single center with the lowest mean serum sodium level over the first 7 days of admission. $\mathrm{Na}_{\max }=$ maximum serum sodium over 7 days of admission, $\mathrm{Na}_{\text {mean }}=$ mean serum sodium over 7 days of admission, $\mathrm{Na}_{\min }=$ minimum serum sodium over 7 days of admission, $\mathrm{Na}_{\mathrm{sD}}=$ standard deviation of serum sodium over 7 days of admission.
} 
Table 2: General and serum sodium characteristics in patients with high NasD and low NasD

\begin{tabular}{|c|c|c|c|}
\hline Variable & $\mathrm{High} \mathrm{Na}_{\mathrm{sD}}(\mathrm{n}=120)$ & Low $\mathrm{Na}_{\text {SD }}(\mathrm{n}=120)$ & $\mathbf{p}$ \\
\hline Age & $43[28-59]$ & $46[32-66]$ & 0.08 \\
\hline APACHE II & 19 [15-24] & $21[16-24]$ & 0.29 \\
\hline ISS & 34 [25-43] & 27 [25-35] & 0.001 \\
\hline Extended IMPACT predicted 6 month-mortality, \% & $26[15-41]$ & 23 [14-38] & 0.34 \\
\hline Diabetes Insipidus, n(\%) & $26(21.7)$ & $9(7.5)$ & 0.002 \\
\hline Osmotherapy, n(\%) & $85(70.8)$ & $55(45.8)$ & $<0.001$ \\
\hline HTS, n(\%) & $62(51.7)$ & $36(30.0)$ & $<0.001$ \\
\hline Mannitol, n(\%) & $54(45.0)$ & $38(31.7)$ & 0.03 \\
\hline EVD, $n(\%)$ & $49(40.8)$ & $33(27.5)$ & 0.03 \\
\hline Neurosurgery, n(\%) & $44(36.7)$ & $46(38.3)$ & 0.79 \\
\hline Admission serum sodium, $\mathrm{mmol} / \mathrm{L}$ & 140 [137-144] & 140 [138-143] & 0.92 \\
\hline $\mathrm{Na}_{\text {mean, }} \mathrm{mmol} / \mathrm{L}$ & $145.3 \pm 6.1$ & $141.6 \pm 3.4$ & $<0.001$ \\
\hline Hypernatremia, n(\%) & $99(82.5)$ & $54(45)$ & $<0.001$ \\
\hline Hyponatremia, n(\%) & $39(32.5)$ & $19(15.8)$ & 0.002 \\
\hline $\mathrm{Na}_{\max }, \mathrm{mmol} / \mathrm{L}$ & 152 [147-157] & 145 [143-148] & $<0.001$ \\
\hline $\mathrm{Na}_{\min }, \mathrm{mmol} / \mathrm{L}$ & 137 [134-140] & $137[136-140]$ & 0.06 \\
\hline \multicolumn{4}{|l|}{ Acute Serum Sodium changes within the first 7 days* } \\
\hline Serum sodium increase $>0.5 \mathrm{mmol} / \mathrm{L} / \mathrm{h}, \mathrm{n}(\%)$ & $95 / 2836(3.3)$ & $59 / 2730(2.2)$ & 0.007 \\
\hline Serum sodium increase $>1 \mathrm{mmol} / \mathrm{L} / \mathrm{h}, \mathrm{n}(\%)$ & 40/2836 (1.4) & $5 / 2730(0.2)$ & $<0.001$ \\
\hline Serum sodium decrease $>0.5 \mathrm{mmol} / \mathrm{L} / \mathrm{h}, \mathrm{n}(\%)$ & $77 / 2836(2.7)$ & $32 / 2730(1.2)$ & $<0.001$ \\
\hline Serum sodium decrease $>1.0 \mathrm{mmol} / \mathrm{L} / \mathrm{h}, \mathrm{n}(\%)$ & $20 / 2836(0.7)$ & $3 / 2730(0.1)$ & $<0.001$ \\
\hline $\mathrm{Na}_{\text {sD }}, \mathrm{mmol} / \mathrm{L}$ & $3.9[3.4-4.8]$ & $2.0[1.7-2.4]$ & $<0.001$ \\
\hline ICU length of stay, days & $15[7-21]$ & 13 [9-19] & 0.74 \\
\hline Hospital length of stay, days & $21[8-34]$ & 20 [13-30] & 0.95 \\
\hline ICU mortality, n(\%) & $33(27.5)$ & $24(20)$ & 0.17 \\
\hline Hospital mortality, n(\%) & $38(31.7)$ & $28(23.3)$ & 0.15 \\
\hline
\end{tabular}

${ }^{*}$ Acute changes in serum sodium are given in number of six-hourly period of time with rate of change greater than 0.5 or $1 \mathrm{mmol} / \mathrm{L} / \mathrm{h}$. High NasD was defined as NasD over the first 7 days of admission higher than median NasD (i.e. $2.8 \mathrm{mmol} / \mathrm{L}$ ). Data are reported as mean $\pm \mathrm{SD}$, median [interquartile ranges] or $\mathrm{n}$ (proportion). APACHE = acute physiology and chronic health evaluation, EVD = extraventricular drain, HTS=hypertonic saline, ICU = 
intensive care unit, IMPACT = international mission for prognosis and analysis of clinical trials in TBI, ISS = injury severity score, $\mathrm{Na}_{\max }=$ maximum serum sodium over 7 days of admission, $\mathrm{Na}_{\text {mean }}=$ mean serum sodium over 7 days of admission, $\mathrm{Na}_{\min }=$ minimum serum sodium over 7 days of admission, $\mathrm{Na}_{\mathrm{SD}}=$ standard deviation of serum sodium over 7 days of admission. 
Table 3: General characteristics and serum sodium variability in hospital survivors and non survivors.

\begin{tabular}{|c|c|c|c|}
\hline Variable & Survivors $(n=174)$ & Non survivors $(n=66)$ & $\mathbf{p}$ \\
\hline Extended IMPACT predicted 6 month-mortality, \% & 21 [13-33] & $38[26-51]$ & $<0.001$ \\
\hline Diabetes Insipidus, n(\%) & $21(12)$ & $14(21)$ & 0.073 \\
\hline Osmotherapy, n(\%) & $93(53)$ & $47(71)$ & 0.013 \\
\hline HTS, n(\%) & $73(42)$ & $25(38)$ & 0.566 \\
\hline Mannitol, n(\%) & $57(33)$ & $34(53)$ & 0.004 \\
\hline Admission serum sodium, $\mathrm{mmol} / \mathrm{L}$ & 140 [137-143] & 140 [138-143] & 0.513 \\
\hline $\mathrm{Na}_{\text {mean, }}, \mathrm{mmol} / \mathrm{L}$ & $142.9 \pm 4.8$ & $144.8 \pm 6.3$ & 0.035 \\
\hline Hypernatremia, $n(\%)$ & $106(61)$ & $47(71)$ & 0.139 \\
\hline Hyponatremia, n(\%) & $43(25)$ & $15(23)$ & 0.748 \\
\hline $\mathrm{Na}_{\max }, \mathrm{mmol} / \mathrm{L}$ & $147[144-151]$ & 149 [144-155] & 0.024 \\
\hline $\mathrm{Na}_{\min }, \mathrm{mmol} / \mathrm{L}$ & $137[135-140]$ & $137[135-141]$ & 0.228 \\
\hline \multicolumn{4}{|l|}{ Acute serum sodium changes within the first 7 days* } \\
\hline Serum sodium increase $>0.5 \mathrm{mmol} / \mathrm{L} / \mathrm{h}, \mathrm{n}(\%)$ & $103 / 4108(2.5)$ & $51 / 1458(3.5)$ & 0.009 \\
\hline Serum sodium increase $>1 \mathrm{mmol} / \mathrm{L} / \mathrm{h}, \mathrm{n}(\%)$ & $27 / 4108(0.7)$ & $18 / 1458(1.2)$ & 0.034 \\
\hline Serum sodium decrease $>0.5 \mathrm{mmol} / \mathrm{L} / \mathrm{h}, \mathrm{n}(\%)$ & $78 / 4108(1.9)$ & $31 / 1458(2.1)$ & 0.590 \\
\hline Serum sodium decrease $>1.0 \mathrm{mmol} / \mathrm{L} / \mathrm{h}, \mathrm{n}(\%)$ & $17 / 4108(0.4)$ & $6 / 1458(0.4)$ & 0.991 \\
\hline $\mathrm{Na}_{\text {sD }}, \mathrm{mmol} / \mathrm{L}$ & $2.7[2.0-3.6]$ & $2.9[2.2-4.2]$ & 0.065 \\
\hline Length of stay, days & 24 [17-38] & 9 [5-15] & - \\
\hline
\end{tabular}

* Acute changes in serum sodium are given in number of six-hourly period of time with rate of change greater than 0.5 or $1 \mathrm{mmol} / \mathrm{L} / \mathrm{h}$. Data are reported as mean $\pm \mathrm{SD}$, median [interquartile ranges] or $\mathrm{n}$ (proportion). EVD = extraventricular drain, HTS = hypertonic saline, ICU = intensive care unit, IMPACT = international mission for prognosis and analysis of clinical trials in TBI, ISS = injury severity score, $\mathrm{Na}_{\max }=$ maximum serum sodium over 7 days of admission, $\mathrm{Na}_{\text {mean }}=$ mean serum sodium over 7 days of admission, $\mathrm{Na}_{\min }=$ minimum serum sodium over 7 days of admission, $\mathrm{NaSD}_{\mathrm{SD}}=$ standard deviation of serum sodium over 7 days of admission 
Table 4: Cox proportional hazards model for 28-day mortality

\begin{tabular}{|c|c|c|c|c|}
\hline Variable & HR & 95\% CI Lower limit & 95\% Cl Upper limit & $\mathbf{P}$ \\
\hline $\mathrm{dNa}_{\text {SD }}$ & 1.27 & 1.01 & 1.61 & 0.048 \\
\hline $\mathrm{dNa} \mathrm{amean}_{\text {}}$ & 1.05 & 0.99 & 1.10 & 0.096 \\
\hline $\mathrm{dNa}_{\max }$ & 1.05 & 0.99 & 1.11 & 0.070 \\
\hline
\end{tabular}

Each variable was individually inserted into the model. Adjustment was made for IMPACT score, the occurrence of diabetes insipidus, daily use of osmotherapy, daily occurrence of hypernatremia and hyponatremia and center (as a random effect). $\mathrm{Cl}=$ confidence interval, $\mathrm{dNa} a_{\max }=$ daily maximum serum sodium, $\mathrm{dNa} a_{\text {mean }}=$ daily mean serum sodium, $\mathrm{dNasD}=$ daily standard deviation of serum sodium 